Article

\title{
Simultaneous Detection of Dihydroxybenzene Isomers Using Electrochemically Reduced Graphene Oxide-Carboxylated Carbon Nanotubes/Gold Nanoparticles Nanocomposite
}

\author{
Angélica Domínguez-Aragón ${ }^{1}\left[\right.$, Rocio B. Dominguez ${ }^{2}$ and Erasto Armando Zaragoza-Contreras ${ }^{1, *(1)}$ \\ 1 Centro de Investigación en Materiales Avanzados, S.C., Miguel de Cervantes No. 120, \\ Chihuahua C.P. 31136, Chih, Mexico; angelica.dominguez@cimav.edu.mx \\ 2 CONACyT-Centro de Investigación en Materiales Avanzados, S.C., Miguel de Cervantes 120, \\ Chihuahua C.P. 31136, Chih, Mexico; berenice.dominguez@cimav.edu.mx \\ * Correspondence: armando.zaragoza@cimav.edu.mx; Tel.: +52-614-439-4811; Fax: +52-614-439-1130
}

Citation: Domínguez-Aragón, A.; Dominguez, R.B.; Zaragoza-

Contreras, E.A. Simultaneous Detection of Dihydroxybenzene Isomers Using Electrochemically Reduced Graphene OxideCarboxylated Carbon Nanotubes/ Gold Nanoparticles Nanocomposite. Biosensors 2021, 11, 321. https:// doi.org/10.3390/bios11090321

Received: 3 August 2021

Accepted: 2 September 2021

Published: 7 September 2021

Publisher's Note: MDPI stays neutral with regard to jurisdictional claims in published maps and institutional affiliations.

Copyright: () 2021 by the authors. Licensee MDPI, Basel, Switzerland. This article is an open access article distributed under the terms and conditions of the Creative Commons Attribution (CC BY) license (https:// creativecommons.org/licenses/by/ $4.0 /)$

\begin{abstract}
An electrochemical sensor based on electrochemically reduced graphene oxide (ErGO), carboxylated carbon nanotubes (cMWCNT), and gold nanoparticles (AuNPs) (GCE/ErGO-cMWCNT/ AuNPs) was developed for the simultaneous detection of dihidroxybenzen isomers (DHB) hydroquinone (HQ), catechol (CC), and resorcinol (RS) using differential pulse voltammetry (DPV). The fabrication and optimization of the system were evaluated with Raman Spectroscopy, SEM, cyclic voltammetry, and DPV. Under optimized conditions, the GCE/ErGO-cMWCNT/AuNPs sensor exhibited a linear concentration range of $1.2-170 \mu \mathrm{M}$ for HQ and CC, and 2.4-400 $\mu \mathrm{M}$ for RS with a detection limit of $0.39 \mu \mathrm{M}, 0.54 \mu \mathrm{M}$, and $0.61 \mu \mathrm{M}$, respectively. When evaluated in tap water and skin-lightening cream, DHB multianalyte detection showed an average recovery rate of $107.11 \%$ and $102.56 \%$, respectively. The performance was attributed to the synergistic effects of the 3D network formed by the strong $\pi-\pi$ stacking interaction between ErGO and cMWCNT, combined with the active catalytic sites of AuNPs. Additionally, the cMWCNT provided improved electrocatalytic properties associated with the carboxyl groups that facilitate the adsorption of the DHB and the greater amount of active edge planes. The proposed GCE/ErGO-cMWCNT/AuNPs sensor showed a great potential for the simultaneous, precise, and easy-to-handle detection of DHB in complex samples with high sensitivity.
\end{abstract}

Keywords: dihydroxybenzene isomers; simultaneous detection; carboxylated carbon nanotubes; electrochemically reduced graphene oxide; nanocomposite; hydroquinone; catechol; resorcinol

\section{Introduction}

The simultaneous detection of dihydroxybenzene isomers (DHB), namely hydroquinone (HQ), catechol (CC), and resorcinol (RS), is of significant concern given their harmful effects on human health. However, due to their great versatility, it is expected that the worldwide production of DHB will continue to grow at a high pace, resulting in high exposure for the population through several pathways such as water and food contamination, environmental pollution, and cosmetic usage. For example, HQ is used in a wide range of industrial activities such as synthesis and formulation of rubbers and plastics, in food, and in cosmetics dedicated to skin lightening due to HQ inhibition over melanin production [1,2]. However, because HQ is a derivative of benzene, the consternation regarding its toxicity and carcinogenic behavior [3-5] has encouraged a significant number of investigations. HQ is also linked to depigmentation of the skin (vitiligium) and conditions in eyes, and in the respiratory system due to high exposure [1]. CC is also a DHB that can be used as an ingredient in cosmetics and pharmaceuticals industries [6]. When absorbed in the gastrointestinal tract, CC can produce renal tube destruction, liver function reduction, and strong central nervous system suppression when exposed to high doses [7]. 
RS is the third DHB, and has been related to angioneurotic edema, eczema, and urticaria [8]. After prolonged exposure to RS, suppression of thyroid hormone synthesis in humans, hematological abnormalities, carcinogenesis, and fatal cases of human fetus poisoning have been observed [9]. Since HQ, CC, and RS are generally used in the production of dyes, cosmetics, pesticides, and some medicines, the DHB often coexist in waste waters and natural waters. Therefore, they are classified as priority toxic pollutants for their high toxicity and the degradation-resistant properties in the environment $[10,11]$.

Consequently, to mitigate their harmful effects on human health, it is of great importance to maintain control of DHB dosage in the recommended limits emitted by the different regulatory entities, such as the World Health Organization (WHO) [12]. Thus, the precise and fast detection of DHB is a major concern for the environmental analysis.

Conventional analytical techniques such as chromatography, fluorescence, and spectrometry are the first choice, but electrochemical multianalyte sensors can be a precise and easy-to-handle alternative for a quick and efficient simultaneous determination of DHB. Previously, biosensors based on polyphenol oxidase have been designed for phenol detection, achieving remarkable sensitivity and selectivity [13]. However, drawbacks such as low chemical and thermal stability along with high cost has promoted detection in non-enzymatic fashion [14]. However, due to their similar structure and closeness of oxidation potential, the multidetection of $\mathrm{HQ}, \mathrm{CC}$, and RS is not feasible with conventional electrodes such as glassy carbon electrodes (GCE), and surface modification is necessary. Intensive research work for novel chemically modified electrodes (CME) for multianalyte detection includes metal-organic frameworks (MOF) [15,16], conductive polymers [17], metal nanoparticles [18], cobalt-phthalocyanine [19], and carbon-based nanomaterials such as graphene and carbon nanotubes (CNT) [20,21].

Among them, hybrids of CNT and graphene have shown high potential for detecting redox molecules [22], given their improved conductivity, large surface area, and catalytic properties compared with either pristine CNTs or GO/graphene [23]. The strong $\pi-\pi$ stacking interaction generated by the 3D network, formed by the combination of graphene of high charge density and CNTs of large surface area, enables synergistic effects with enhanced mechanical, optical, electrical, and electrochemical properties [24].

Usually, for ease of synthesis, multi-walled carbon nanotubes (MWCNT) are included instead of single-walled carbon nanotubes (SWCNT), showing porous structure, high surface area, excellent chemical stability, good mechanical properties, and ability to promote electron transfer reactions [25]. However, since MWCNT are insoluble, the processability for surface modification can be difficult. To overcome this, the carboxyl functionalization of MWCNT can enhance its hydrophilicity, making it more dispersible to prepare a uniform electrode layer. Carboxylated MWCNT (cMWCNT) have shown higher attachment properties due to the functional groups on their surface, which help to generate a more homogeneous surface with better electrochemical activity [26]. Additionally, the carboxylation of MWCNT produces an improved electrocatalytic activity in the material compared with unmodified CNT.

On the other hand, the preparation of CME by electrochemical techniques offers advantages such as environmental safety, simplified synthesis steps, and low reagent consumption. Carbon-based nanocomposites of electrochemically reduced graphene oxide (ErGO) and MWCNT can be prepared within a single step, avoiding common drawbacks such as agglomeration and restacking of layers. Moreover, the ErGO-MWCNT nanocomposite can be used as an excellent scaffold for catalytic nanomaterials deposition, such as gold nanoparticles (AuNPs) [20]. The AuNPs provide additional features such as excellent electrical properties, large surface-to-volume ratio, and high surface reaction activity, resulting in a high-performance electrode surface [27].

In this work, we propose a CME for simultaneous detection of $\mathrm{HQ}, \mathrm{CC}$, and RS using an ErGO-cMWCNT/AuNPs nanocomposite prepared by successive electrochemical steps. Surface characterization revealed a fast electron transfer rate constant, high charge transfer, and excellent analytical response towards the detection of DHB. The proposed sensor was 
also demonstrated for detection in environmental and cosmetic samples, showing excellent accuracy regarding the HQ, CC, and RS content.

\section{Materials and Methods}

\subsection{Characterization}

Morphology was analyzed with a JEOL 300-S (Tokyo, Japan) scanning electron microscope (SEM), and Raman spectroscopy was analyzed using a microspectrometer (Horiba, LabRAM-HR) (Horiba, Kyoto, Japan). A three-electrode arrangement, including a GCE $(\varnothing=3 \mathrm{~mm})$, a Pt wire, and an $\mathrm{Ag} / \mathrm{AgCl}$, were used as the working electrode, counter electrode, and reference electrode, respectively. Cyclic voltammetry (CV), electrochemical impedance spectroscopy (EIS), and differential pulse voltammetry (DPV) techniques were performed using an EmStat3 + blue (PalmSens, Houten, The Netherlands) potentiostat.

\subsection{Materials and Reagents}

$\mathrm{HAuCl}_{4} \cdot 3 \mathrm{H}_{2} \mathrm{O}, \mathrm{K}_{4}\left[\mathrm{Fe}(\mathrm{CN})_{6}\right], \mathrm{K}_{3}\left[\mathrm{Fe}(\mathrm{CN})_{6}\right], \mathrm{HQ}, \mathrm{CC}$, and RS were obtained from Sigma Aldrich (St. Louis, MO, USA). $\mathrm{H}_{2} \mathrm{SO}_{4}$ and $\mathrm{HNO}_{3}$ were provided from Fermont (Monterrey, Nuevo León, Mexico). Phosphate buffer solution (PBS) (0.01 M) was prepared from $\mathrm{NaCl}$, $\mathrm{KCl}, \mathrm{Na}_{2} \mathrm{HPO}_{4}$, and $\mathrm{KH}_{2} \mathrm{PO}_{4}$ (Sigma-Aldrich, St. Louis, MO, USA). GO was prepared using the Hummers method [28], and the cMWCNT were carboxylated by acid treatment [29]. A skin-lightening cosmetic cream at $4 \%$ of HQ (Bustillos Laboratory, Mexico D.F, Mexico) was obtained at a local store.

\subsection{GCE Modification with ErGO-cMWCNT/AuNPs Nanocomposite}

Prior to modification, GCE was polished with alumina suspension $(0.05 \mu \mathrm{m})$ and rinsed with deionized water, followed by sonication in ethanol and deionized water. Then, $4 \mu \mathrm{L}$ of GO $(5 \mathrm{mg} / \mathrm{mL})$ and cMWCNT $(5 \mathrm{mg} / \mathrm{mL})(1: 1)$ mixture were drop cast on the GCE surface and allowed to dry. CV was carried out on the GCE/GO-cMWCNT in PBS $(0.01 \mathrm{M}, \mathrm{pH} 7.4)$ at a potential window from -1.5 to $0.5 \mathrm{~V}$ and scan rate of $100 \mathrm{mV} \mathrm{s}^{-1}$ during 20 cycles of reduction. The modified electrode GCE/ErGO-cMWCNT was washed with distilled water and dried at room temperature.

The AuNPs were electrodeposited on the nanocomposite to increase the electrochemically active surface. Briefly, the AuNPs were electrodeposited from a $1 \mathrm{mM}$ solution of $\mathrm{HAuCl}_{4}$ in $0.1 \mathrm{M} \mathrm{H}_{2} \mathrm{SO}_{4}$ using a constant potential of $-0.5 \mathrm{~V}$ for $80 \mathrm{~s}$.

Finally, the GCE/ErGO-cMWCNT/AuNPs was rinsed with distilled water and dried. AuNPs were also electrodeposited on GCE/ErGO, GCE/cMWCNT, and GCE using the same conditions to corroborate synergistic effects of the nanocomposite. Figure 1 illustrates the steps of the GCE modification.

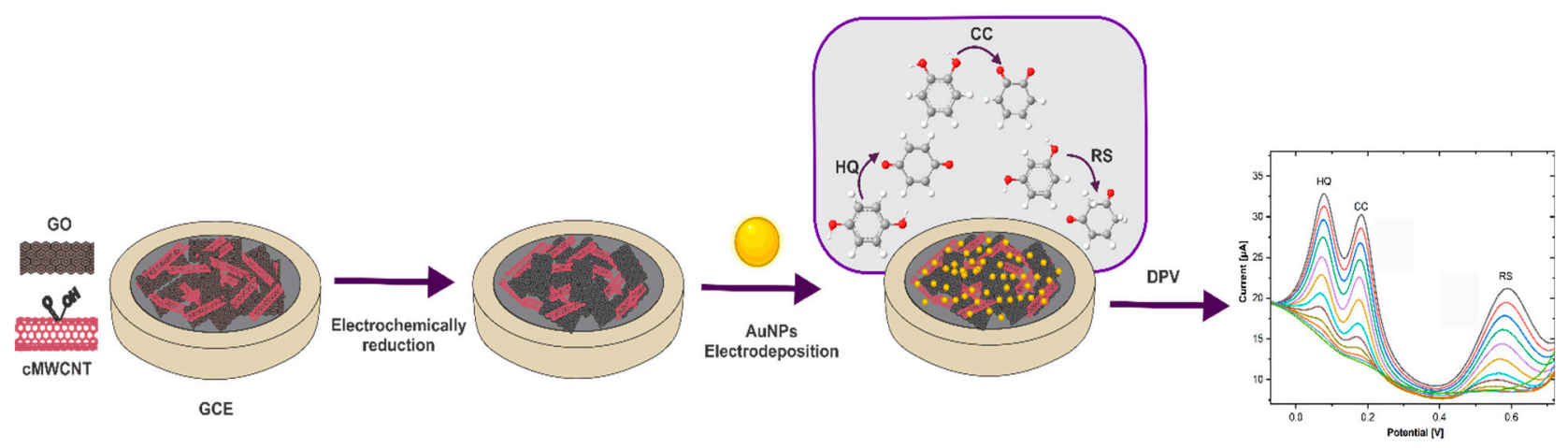

Figure 1. Scheme of the step-by-step preparation of the GCE/ErGO-cMWCNT/AuNPs sensor for simultaneous detection of DHB. 


\subsection{Electrochemical Measurements and Real Sample Analysis}

The electrochemical analysis was performed in a cell containing $25 \mathrm{~mL}$ of PBS $0.01 \mathrm{M}$ at $\mathrm{pH}$ 7.0. Different concentrations of HQ, CC, and RS were measured both separately and simultaneously by DPV. The potential window was from -0.4 to $0.9 \mathrm{~V}$ at a scan rate of $0.05 \mathrm{~V} \mathrm{~s}^{-1}$. HQ, CC, and RC were detected simultaneously in tap water diluted in PBS (0.01 M, pH 7) (X10). A skin-lightening cream was diluted in PBS (0.01 M, pH 7) (X10) to obtain three concentrations of HQ. The cream was spiked with CC and RS to corroborate the simultaneous determination of these isomers.

\section{Results and Discussion}

3.1. Materials Characterization

\subsubsection{SEM}

The morphology of the ErGO-cMWCNT and ErGO-cMWCNT/AuNPs composites was characterized by SEM. The electrochemical reduction of GO over the GCE produced numerous interconnected layers partially folded and wrinkled, as observed in previous ErGO morphology [30]. ErGO sheets, partially wrinkled, were formed attached parallel to the electrode surface. ErGO-cMWCNT formed an interconnected porous network, increasing the surface roughness, as shown in Figure 2A. The ErGO-cMWCNT also served as a scaffold for growing well-dispersed AuNPs of around $20-30 \mathrm{~nm}$ in diameter, as observed in Figure 2B. AuNPs were equally prone to deposit over the basal plane of ErGO sheets and tubular cMWCNT, forming a favorable pathway in the composite for electronic transfer. The EDS analysis confirmed (Figure 2C) the presence of Au element in the nanocomposite.
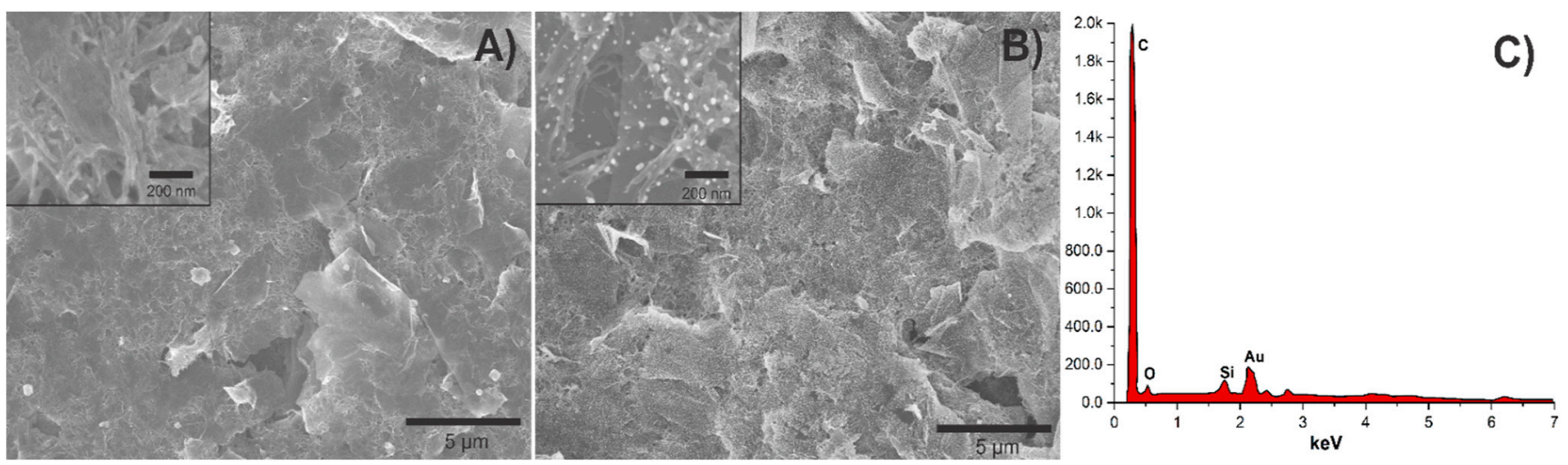

Figure 2. SEM images of (A) ErGO-cMWCNT, (B) ErGO-cMWCNT/AuNPs, and (C) EDS of ErGO-cMWCNT/AuNPs.

\subsubsection{Raman}

Raman spectroscopy is important to characterize carbon-based materials such as graphene and MWCNT, since it provides information on structural defects. Figure 3 shows the $\mathrm{D}$ band around $1325 \mathrm{~cm}^{-1}$, which is related to the degree of defects and disorder in the graphene structure, and the $\mathrm{G}$ band around $1581 \mathrm{~cm}^{-1}$ corresponding to the $\mathrm{sp}^{2}$ vibrational plane of the bonded carbon atoms in a $2 \mathrm{D}$ hexagonal lattice [31]. The $\mathrm{I}_{\mathrm{D}} / \mathrm{I}_{\mathrm{G}}$ ratio was calculated to determine the degree of disorder and the average size of $\mathrm{sp}^{2}$ domains in the prepared materials. The $\mathrm{I}_{\mathrm{D}} / \mathrm{I}_{\mathrm{G}}$ ratios of GO, ErGO, ErGO-cMWCNT, and ErGO-cMWCNT/AuNps were 1.04, 1.53, 1.21, and 1.22, respectively. The $\mathrm{I}_{\mathrm{D}} / \mathrm{I}_{\mathrm{G}}$ of GO confirms the presence of in-plane $\mathrm{sp}^{2}$ domains and $\mathrm{sp}^{3}$ hybridization due to the presence of oxygenated groups. The increased ratio in ErGO indicated the introduction of defects in the structure during the removal of oxygen functionalities after electrochemical reduction (Figure $\mathrm{S} 1$ ). $\mathrm{I}_{\mathrm{D}} / \mathrm{I}_{\mathrm{G}}$ values for ErGO-cMWCNT and ErGO-cMWCNT/AuNPs are lower than of ErGO, which may indicate that cMWCNT and AuNPs reduced the defect density by filling the spaces left after the remotion of oxygen functionalities. 


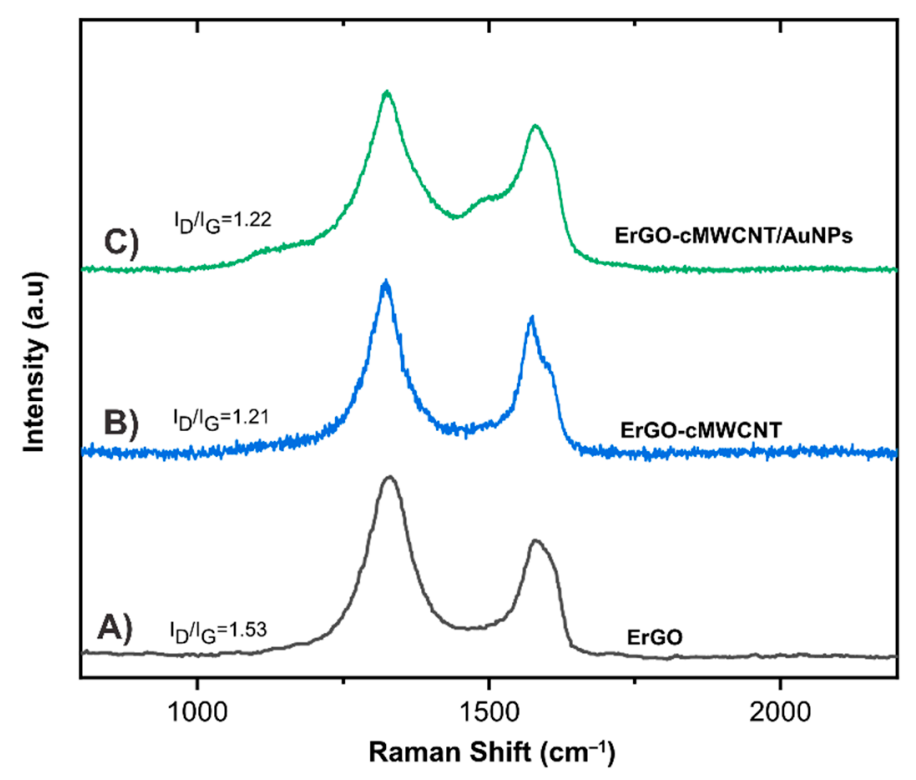

Figure 3. Raman spectra of (A) ErGO, (B)ErGO-cMWCNT, (C) ErGO-cMWCNT/AuNPs.

\subsection{Electrochemical Characterization}

Figure $4 \mathrm{~A}$ shows the $\mathrm{CVs}$ of all CME and the bare GCE in $\left[\mathrm{Fe}(\mathrm{CN})_{6}\right]^{-3 /-4}$ as the redox probe to study the electrochemical behavior of the modified surfaces at a scan rate of $100 \mathrm{mV} \mathrm{s}^{-1}$. All the modifications showed well-defined redox peaks for the $\left.\mathrm{Fe}(\mathrm{CN})_{6}\right]^{-3 /-4}$ redox couple. The values of the peak-to-peak separation $\left(\Delta \mathrm{E}_{\mathrm{p}}\right)$ and the current intensity of the anodic peak $\left(\mathrm{I}_{\mathrm{pa}}\right)$ were also determined for GCE $\left(\Delta \mathrm{E}_{\mathrm{p}}=219 \mathrm{mV}\right.$, $\left.\mathrm{I}_{\mathrm{pa}}=72 \mu \mathrm{A}\right), \mathrm{GCE} / \mathrm{AuNP}\left(\Delta \mathrm{E}_{\mathrm{p}}=109 \mathrm{mV}, \mathrm{Ipa}=90 \mu \mathrm{A}\right), \mathrm{GCE} / \mathrm{ErGOAuNP}(\Delta \mathrm{Ep}=109 \mathrm{mV}$, Ipa $=94.42 \mu \mathrm{A}), \mathrm{GCE} / \mathrm{cMWCNT} / \operatorname{AuNPs}\left(\Delta \mathrm{E}_{\mathrm{p}}=89 \mathrm{mV}, \mathrm{I}_{\mathrm{pa}}=87 \mu \mathrm{A}\right)$, and GCE/ErGOcMWCNT/AuNPs $\left(\Delta \mathrm{E}_{\mathrm{p}}=89 \mathrm{mV}, \mathrm{I}_{\mathrm{pa}}=101 \mu \mathrm{A}\right)$.
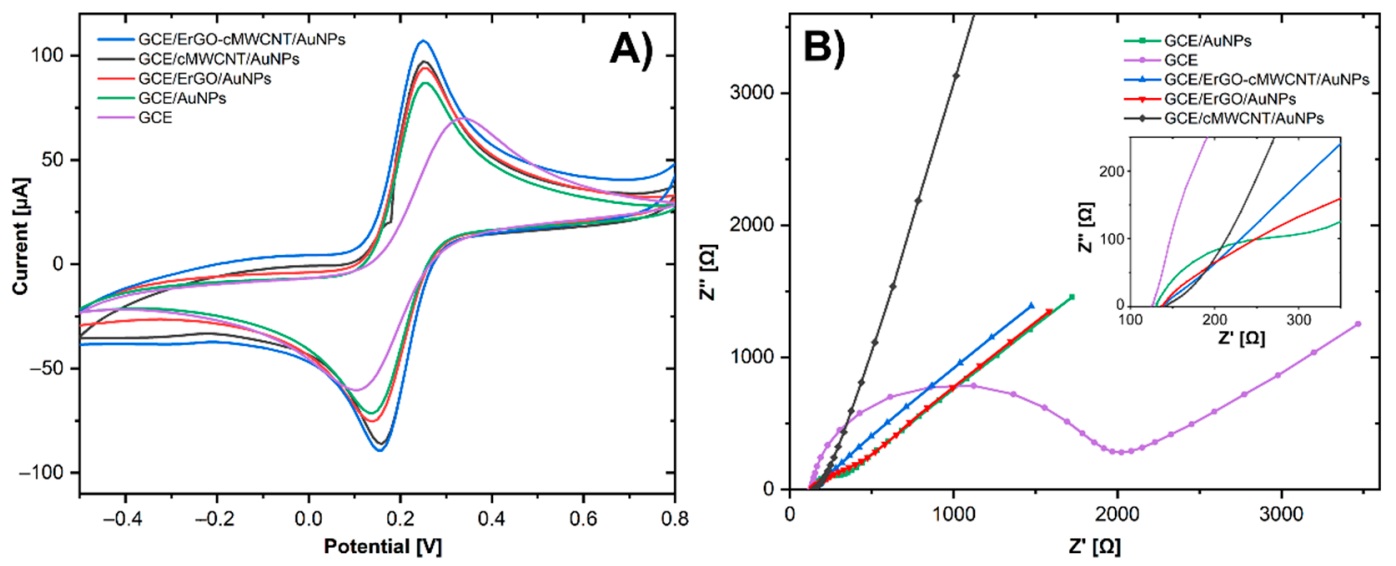

Figure 4. (A) $\mathrm{CV}$ in $5.0 \mathrm{mM}\left[\mathrm{Fe}(\mathrm{CN})_{6}\right]^{-3 /-4}$ containing PBS $0.01 \mathrm{M}$ at $100 \mathrm{mV} \mathrm{s}^{-1}$, (B) EIS in $5.0 \mathrm{mM}\left[\mathrm{Fe}(\mathrm{CN})_{6}\right]^{-3 /-4}$ containing PBS $0.01 \mathrm{M}$.

The bare GCE showed the largest $\Delta \mathrm{E}_{\mathrm{p}}$, which was significantly reduced with all the surface modifications, especially with ErGO-cMWCNT/AuNPs, which implies that the hybrid-based nanocomposite promotes a faster electronic transfer [32]. The results reveal great electrocatalytic features of GCE/ErGO-cMWCNT/AuNPs, due to the synergistic effect of AuNPs, ErGO, and cMWCNT, which improved the electron transfer rate, accelerating the oxidation/reduction response of the redox probe on the electrode surface [33]. 
The electrochemically active surface area of the various modified electrodes was evaluated using $\mathrm{CV}$, varying the scan rates and using the $\left[\mathrm{Fe}(\mathrm{CN})_{6}\right]^{-3 /-4}$ solution (Figure S2). The surface area was calculated using the Randles-Sevick Equation (1):

$$
I_{p a}=2.69 \times 10^{5} A D \frac{1}{2} n^{3 / 2} v \frac{1}{2} C
$$

where $n$ is the number of electrons participating in the redox reaction $(n=1), A$ is the electroactive area $\left(\mathrm{cm}^{2}\right), v$ is the scan rate $\left(\mathrm{V} \mathrm{s}^{-1}\right)$, and $D$ and $C$ are the diffusion coefficient $\left(6.7 \times 10^{-6} \mathrm{~cm}^{2} \mathrm{~s}^{-1}\right)$ and the concentration $\left(\mathrm{mol} \mathrm{cm}{ }^{-3}\right)$ of the redox probe, respectively [34]. The $A$ was calculated using the slope of $I_{p a}$ versus the root of scan rate $\left(v^{1 / 2}\right)$. The resulting electroactive surfaces were GCE $\left(0.055 \mathrm{~cm}^{2}\right), \mathrm{GCE} / \mathrm{AuNP}\left(0.081 \mathrm{~cm}^{2}\right), \mathrm{GCE} / \mathrm{ErGO} / \mathrm{AuNPs}$ $\left(0.088 \mathrm{~cm}^{2}\right), \mathrm{GCE} / \mathrm{cMWCNT} / \mathrm{AuNPs}\left(0.095 \mathrm{~cm}^{2}\right)$, and GCE/ErGO-cMWCNT/AuNPs $\left(0.11 \mathrm{~cm}^{2}\right)$.

The results showed that GCE/ErGO-cMWCNT/AuNPs had the most prominent active electrochemical area among the CMEs, increasing the active surface of the GCE by $100 \%$. The ErGO-cMWCNT/AuNP improved electrochemical response can be attributed to the generation of 3D networks formed by interconnected carbon nanotube-graphene hybrids and AuNPs, with well-defined nanopores [24,35]. The nanostructures led to a synergistic effect in enhanced conductivity, electroactivity, and enlarged electroactive surface area with multiple active sites, making it optimal for transduction in electrochemical sensing.

\subsection{Electrochemical Detection of Dihydroxybenzene Isomers}

EIS is an effective tool for studying the electrode-electrolyte interface properties of CMEs. In the Nyquist graph, the semicircular section at high frequency permits calculating the charge transfer resistance $\left(R_{c t}\right)$, while the linear part at low frequency is associated with the diffusion control process [15]. Figure 4B shows the EIS of the CMEs recorded in $5 \mathrm{mM}$ of $\left[\mathrm{Fe}(\mathrm{CN})_{6}\right]^{-3 /-4}$, showing values of the $\mathrm{R}_{\mathrm{ct}}$ of GCE $(1788 \Omega)$, GCE/AuNPs (135.28 $\Omega)$, GCE/ErGO/AuNPs (90 $\Omega)$, GCE/cMWCNT/AuNPs (26.97 $\Omega)$, GCE/ErGOcMWCNT/AuNPs $(24.2 \Omega)$. The bare GCE has the largest $R_{\mathrm{ct}}$, but significantly decreased with all the modifications, especially with GCE/ErGO-cMWCNT/AuNPs, indicating that the incorporation of these materials improved the conductivity and led to faster charge transfer kinetics. These results evidenced the synergistic effect between ErGO, cMWCNT, and AuNPs, enabling a significant number of active sites for chemical reactions.

To study the electrochemical features of the DHB, the CME was tested in a PBS solution (0.01 M, pH 7) containing $0.2 \mathrm{mM}$ of HQ, CC, and RS by CV and DPV. Figure 5A shows the $\mathrm{CV}$ of the electrodes. The overlapping redox peak of HQ and CC in GCE was attributed to the slow electron dynamics and limited diffusion of the isomers at the electrode surface [34]. The introduction of AuNPs and ErGO/AuNPs to the GCE induced a slight enhancement, which enabled the separation of the CC and HQ redox peak, showing three poorly defined oxidation peaks. In addition, the GCE modification with cMWCNT/AuNPs and ErGOcMWCNT/AuNPs drastically improved the electrochemical performance, enabling the obtention of three well-separated oxidation peaks at $0.11 \mathrm{~V}, 0.22 \mathrm{~V}$, and $0.6 \mathrm{~V}$, attributed to the oxidation of HQ, CC, and RS. HQ and CC exhibited a reversible quinolinic form with a pair of redox peaks, while the oxidation reaction of RS is irreversible. This is attributed to the charge density, which is different in each isomer due to the position of the two hydroxyl functional groups on the benzene ring [33].

The electrochemical response of DHB at the different electrodes by DPV (Figure 5B) coincides appropriately with those measured by CV. It is clearly noticeable that the electrochemical activity of the GCE/ErGO-cMWCNT/AuNPs nanocomposite was superior for the detection of the three isomers than those at separate materials. The 3D network formed by the strong $\pi-\pi$ stacking interaction between ErGO and cMWCNT, with well-defined nanopores and active catalytic sites of AuNPs, facilities the adsorption of the DHB and the electron transfer efficiency between the electroactive analytes and the CME. Additionally, to corroborate that carboxylation improves the electroactive performance of the pristine MWCNT, the nanocomposite was elaborated with either MWCNT or cMWCNT. The CME 
with the pristine MWCNT leads the separation of the CC and HQ oxidation peaks, but poorly defined (Figure 5C), whilst with cMWCNT (Figure 5D), showed separated and well-defined peaks for each DHB.

Moreover, the nanocomposite with the cMWCNT exhibited an increased current associated with the induction of the carboxylic groups to the MWCNT structure, facilitating the adsorption of organic molecules on the electrode surface. The $\pi-\pi$ interaction between the phenyl structure of DHB and the hexagonal carbon structure and carboxyl groups of cMWCNT promotes the electron transfer [36]. It has been reported that the acid functionalization of MWCNT breaks the long nanotubes into shorter ones, increasing the number of edge plans, which provide a greater available area to the electroactive reactions, promoting a faster charge-transfer rate with better electrocatalytic activity [37,38]. Besides, the aggregation of graphene sheets was avoided not only by the $\pi-\pi$ stacking interactions between the ErGO sheets and the walls of the cMWCNT but also by the steric barrier from the carboxylic groups of cMWCNT [39]. Moreover, the distribution of the cMWCNT on the graphene surface led to a larger anchoring surface area for AuNPs. Consequently, the highest electrocatalytic activity for the oxidation of $\mathrm{HQ}, \mathrm{CC}$, and RS was obtained with GCE/ErGO-cMWCNT/AuNPs nanocomposite, corroborating the synergistic effect of the components for enhancing electroactivity.
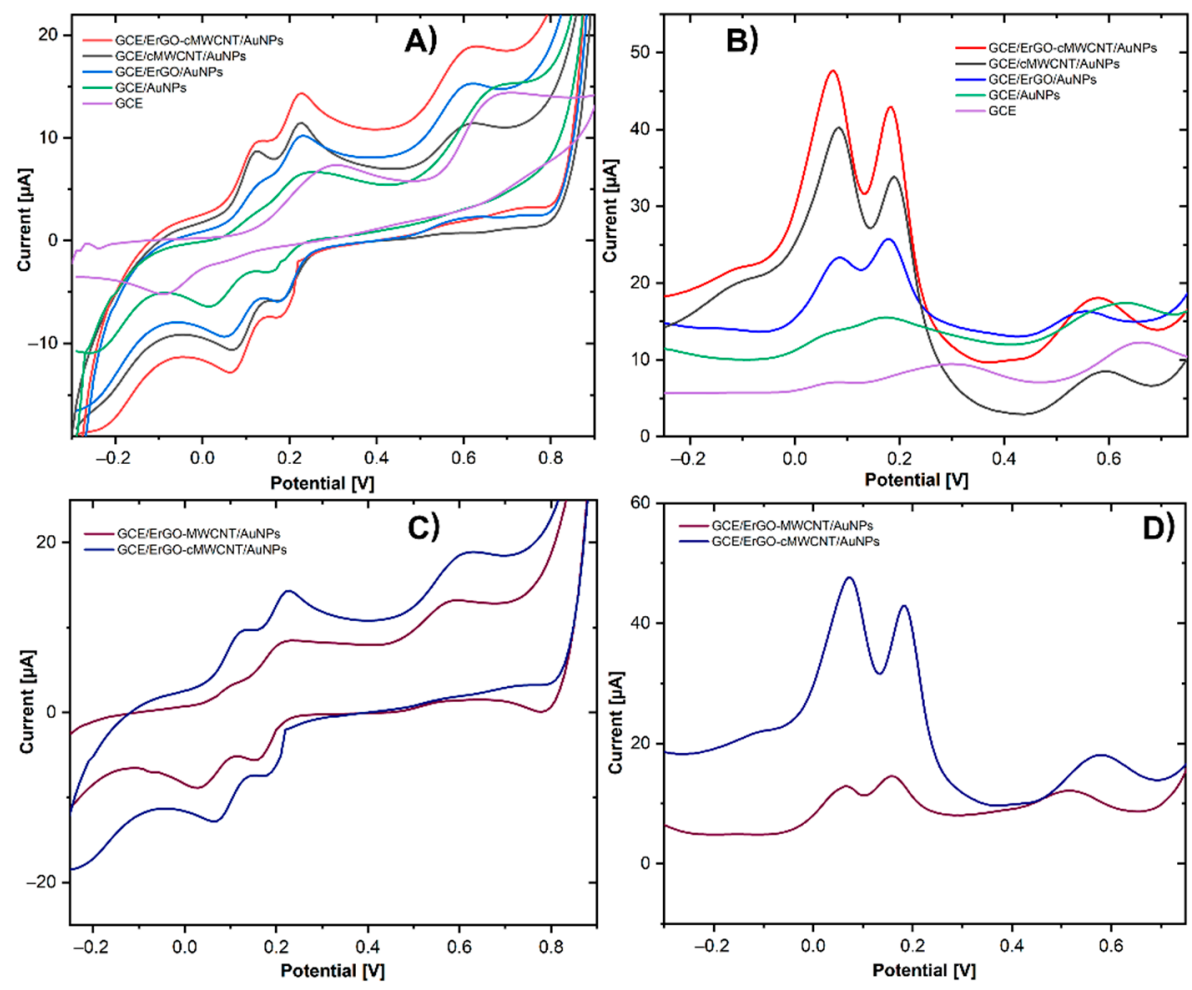

Figure 5. (A,C) Cyclic voltammetry of modified GCE electrodes in HQ, CC, and RS $0.2 \mathrm{mM}$ in PBS $0.01 \mathrm{M}$ at $\mathrm{pH}$ 7. (B,D) Differential pulse voltammetry of modified GCE electrodes in HQ, CC, and RS $0.2 \mathrm{mM}$ in PBS 0.01 M at pH 7.

\subsection{Effect of $\mathrm{pH}$ and Scan Rate}

The electrochemical response of phenolic compounds is influenced by the $\mathrm{pH}$ because it affects the involvement of proton transference in the redox process [25]. Hence, the effect of $\mathrm{pH}$ on the electrochemical response of $\mathrm{HQ}, \mathrm{CC}$, and $\mathrm{RS}$ was evaluated by $\mathrm{CV}$ in the $\mathrm{pH}$ range of 5.5-8.0. Figure 6 shows the effects of the $\mathrm{pH}$ value on the electrochemical response of HQ, CC, and RS at the GCE/ErGO-cMWCNT/AuNPs. The potential of the oxidation peak $\mathrm{E}_{\mathrm{pa}}$ at the DHB isomers shifted negatively as the $\mathrm{pH}$ increased, demonstrating that the protons were directly involved in the redox process [40]. The regression equations for three DHB isomers are as follows: HQ: $\mathrm{E}_{\mathrm{pa}}(\mathrm{V})=-0.0578 \mathrm{pH}+0.5241\left(\mathrm{R}^{2}=0.9929\right), \mathrm{CC}$ : 
$\mathrm{E}_{\mathrm{pa}}(\mathrm{V})=-0.0575 \mathrm{pH}+0.6295\left(\mathrm{R}^{2}=0.9917\right)$, and RS: $\mathrm{E}_{\mathrm{pa}}(\mathrm{V})=-0.0548 \mathrm{pH}+0.999$ $\left(R^{2}=0.9934\right)$.
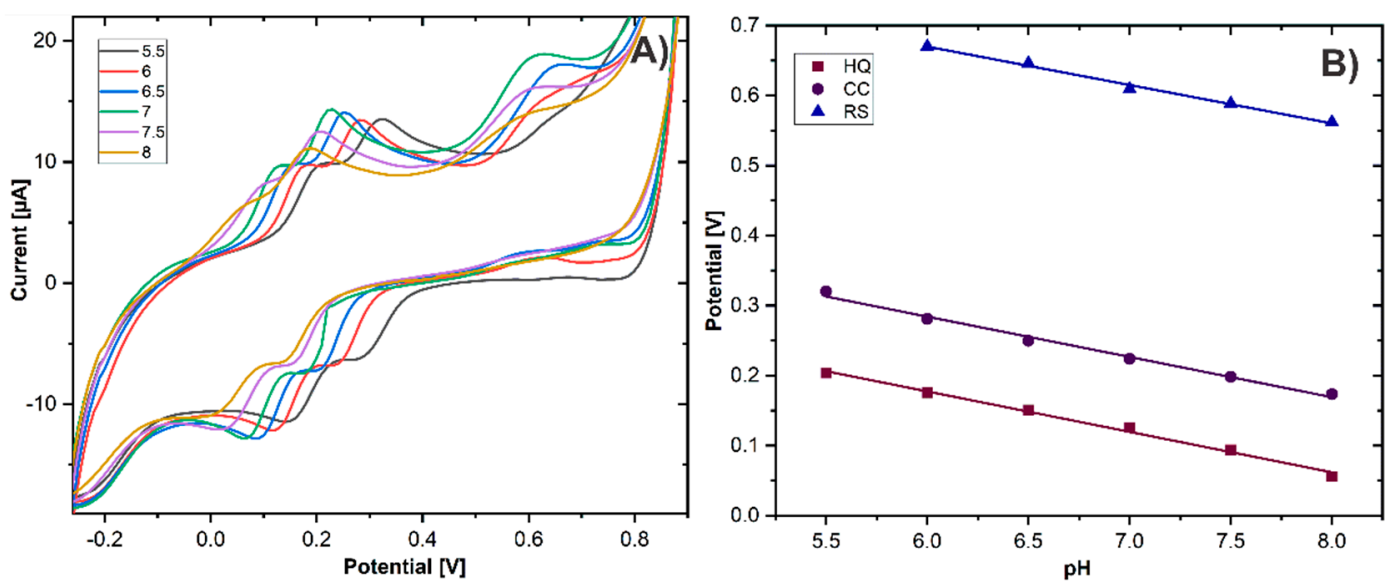

Figure 6. (A) Cyclic voltammetry of GCE/ErGO-cMWCNT/AuNPs for a mixture of $0.2 \mathrm{mM}$ of HQ, CC, and RS in different $\mathrm{pH}$ solutions at $50 \mathrm{mV} \mathrm{s}^{-1}$. (B) Plots of effects of anodic peak potential vs. $\mathrm{pH}$.

The slopes of the three regression equations were $-0.0578 \mathrm{~V} \mathrm{pH}^{-1},-0.0575 \mathrm{~V} \mathrm{pH}^{-1}$, and $-0.0548 \mathrm{~V} \mathrm{pH}^{-1}$ for $\mathrm{HQ}, \mathrm{CC}$, and $\mathrm{RS}$, respectively. These values are very close to the theoretical value of $-0.059 \mathrm{~V} \mathrm{pH}^{-1}$ obtained from the Nernst equation.

The results indicated that an equal number of protons and electrons took place in the redox reaction of HQ, CC, and RS [41], which is in agreement with previous works [33,34]. Based on this, the reaction mechanism of the DHB isomers is illustrated in Figure 7. Furthermore, within the $\mathrm{pH}$ range from 5.5 to 8.0, the maximum current intensity was achieved at $\mathrm{pH}$ 7. Thus, to obtain optimal sensitivity and selectivity, $\mathrm{pH} 7.0$ was chosen for the simultaneous detection of $\mathrm{HQ}, \mathrm{CC}$, and RS.<smiles>O=C1C=CC(=O)C=C1</smiles><smiles>O=C1C=CC2=C[C+]=C(O)C(=C1O)C(=O)C=C2</smiles><smiles>O=C1CC=C(C=CC=[W])C(=O)C1</smiles>

Figure 7. The electrooxidation mechanism of $\mathrm{HQ}, \mathrm{CC}$, and RS.

The electrooxidation process of $\mathrm{DHB}$ was studied by $\mathrm{CV}$ at scanning rates from 20 to $100 \mathrm{mV} \mathrm{s}^{-1}$ using $0.2 \mathrm{mM} \mathrm{HQ}, \mathrm{CC}$, and RS in 0.01M PBS, pH 7. As shown in Figure 8A, with the increasing scan rate, the redox peak currents of HQ, CC, and RS increased gradually. The linear relationship between the scan rate square and the anodic peak current (Figure 8B) confirmed that the electrooxidation process of the DHB at GCE/ErGO-cMWCNT/AuNPs is regulated by the diffusion-controlled electrochemical process [42]. The obtained regressions are expressed by HQ: $\mathrm{I}_{\mathrm{pa}}(\mu \mathrm{A})=59.128 \mathrm{v}^{1 / 2}\left(\mathrm{~V} \mathrm{~s}^{-1}\right)^{1 / 2}-3.8945\left(\mathrm{R}^{2}=0.997\right), \mathrm{CC}: \mathrm{I}_{\mathrm{pa}}(\mu \mathrm{A})=$ $81.139 \mathrm{v}^{1 / 2}\left(\mathrm{~V} \mathrm{~s}^{-1}\right)^{1 / 2}-4.4874\left(\mathrm{R}^{2}=0.9951\right)$, and RS: $\mathrm{I}_{\mathrm{pa}}(\mu \mathrm{A})=97.634 \mathrm{v}^{1 / 2}\left(\mathrm{~V} \mathrm{~s}^{-1}\right)^{1 / 2}+$ $1.2542\left(R^{2}=0.995\right)$. 

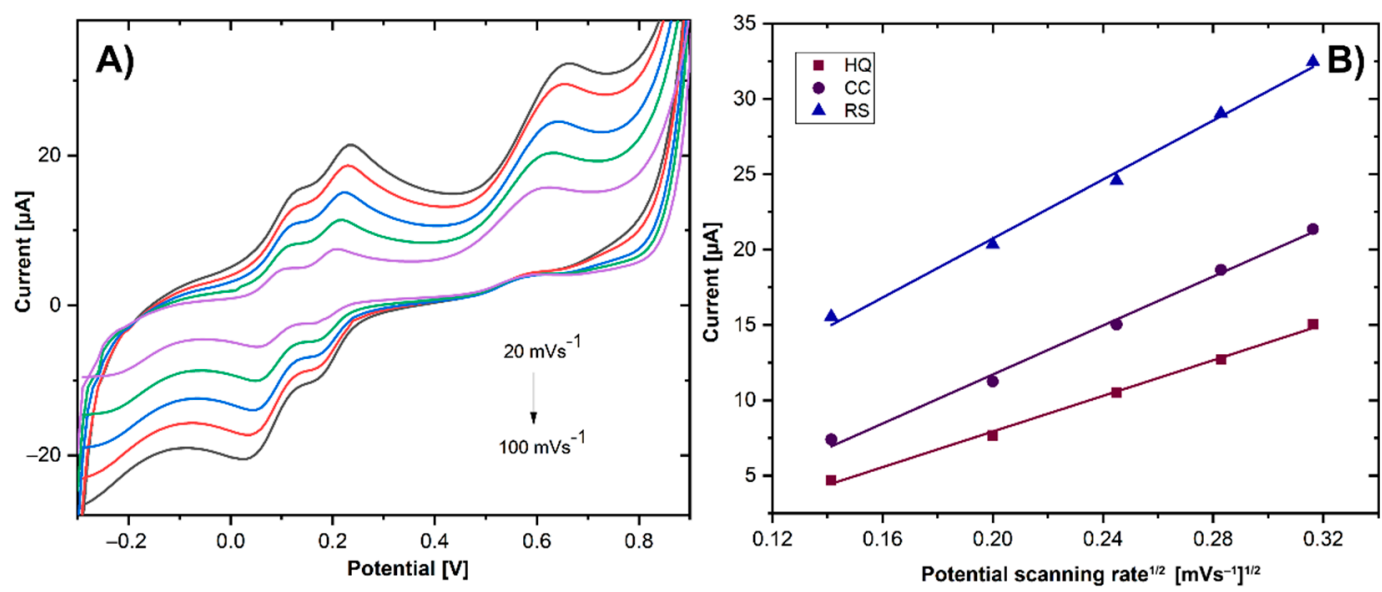

Figure 8. (A) Cyclic voltammetry of GCE/ErGO-cMWCNT/AuNPs in presence of HQ, CC, and RS at pH 7.0 with different scan rates. (B) Plots of effects of anodic peak potential vs. $v^{1 / 2}$.

Moreover, the potentials of the oxidation peaks of $\mathrm{HQ}, \mathrm{CC}$, and RS shifted to a more positive position, and the reduction peak potentials of HQ and CC shifted negatively with the increase in the scan rate. The shift of the peak potentials is associated with the size of the diffusion layer, which creates an internal resistance at the electrode-electrolyte interface [43]. Hence, the current is noticeably higher at the electrode surface when the potential is swept at higher scan rates [44].

According to Laviron's theory [45], the charge-transfer coefficient $(\alpha)$ and the apparent heterogeneous electron transfer rate constant $\left(\mathrm{K}_{\mathrm{s}}\right)$ were calculated. The details of the equations are shown in the Supplementary Material. The $\alpha$ was calculated to be 0.574 , 0.6103 , and 0.41 , and the values of $\mathrm{k}_{\mathrm{s}}$ were $0.693 \mathrm{~cm} \mathrm{~s}^{-1}, 0.973 \mathrm{~cm} \mathrm{~s}^{-1}$, and $0.49 \mathrm{~s}^{-1}$ for $\mathrm{HQ}, \mathrm{CC}$, and RS, respectively. These values show that the kinetics of charge-transfer are energetically favorable on the GCE/ErGO-cMWCNT/AuNPs surface.

\subsection{Individual and Simultaneous Determination of $H Q, C C$, and RS}

The quantitative analysis of HQ, CC, and RS on GCE/ErGO-cMWCNT/AuNPs was performed using DPV under optimized $\mathrm{pH}$ conditions. For single detection, the concentration of a given analyte was varied, and the other two were kept constant. Figure 9A shows the selective detection of HQ in the presence of $25 \mu \mathrm{M}$ of CC and $50 \mu \mathrm{M}$ of RS, with a typical response observed at $0.073 \mathrm{~V}$. The peak current increased linearly with the HQ level in a range from 1.2 to $260 \mu \mathrm{M}$, while there was no evident increment in the response of the other analytes. Similarly, Figure 9B shows CC concentrations measured with $25 \mu \mathrm{M}$ of $\mathrm{HQ}$ and $50 \mu \mathrm{M}$ of RS in the solution. The peak current of CC was registered at $0.18 \mathrm{~V}$, showing a linear response corresponding to $\mathrm{CC}$ concentrations without the interference of HQ and CC. The same behavior was observed for the current peak of RS at $0.58 \mathrm{~V}$ in the presence of $25 \mu \mathrm{M}$ of $\mathrm{HQ}$ and $25 \mu \mathrm{M}$ of CC, although a more comprehensive linear range was registered from 1.2 to $400 \mu \mathrm{M}$. The electrochemical reactions of the three DHB performed on the CME exhibited no influence on each other. The inset of Figure 9A-C exhibits the calibration curves of the anodic peak vs. the DHB concentration. The linear regression obtained for the single detection were $\mathrm{HQ}: \mathrm{I}_{\mathrm{pa}}(\mu \mathrm{A})=124.57 \mathrm{C}_{\mathrm{HQ}}(\mu \mathrm{M})+18.28$ $\left(R^{2}=0.992\right), C C: I_{p a}(\mu A)=137.02 C_{C C}(\mu M)+12.39\left(R^{2}=0.993\right)$, and RS: $I_{p a}(\mu A)=41.27$ $C_{R S}(\mu M)+6.0\left(R^{2}=0.992\right)$. The detection limits obtained for the single detection were 0.66 , 0.84 , and $0.39 \mu \mathrm{M}$ for $\mathrm{HQ}, \mathrm{CC}$, and RS, respectively. 

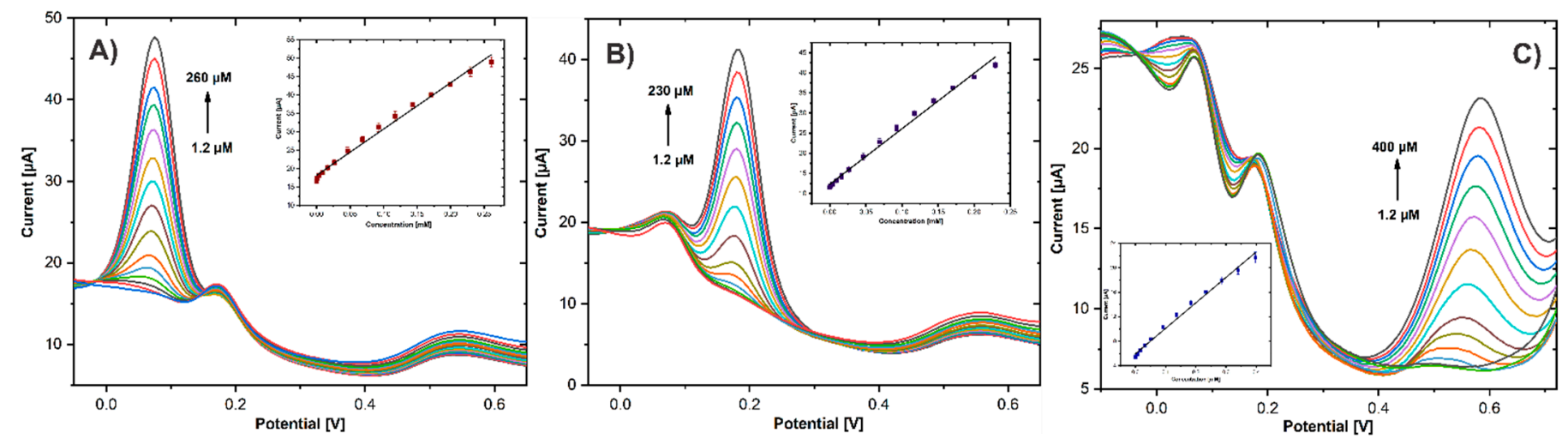

Figure 9. DPVs of GCE/ErGO-cMWCNT/AuNPs in 0.01 PBS (pH 7.0) containing (A) $25 \mu \mathrm{M} \mathrm{CC}, 50 \mu \mathrm{M}$ RS, and different concentrations of HQ; (B) $25 \mu \mathrm{M} \mathrm{HQ}, 50 \mu \mathrm{M}$ RS, and different concentrations of CC; (C) $25 \mu \mathrm{M} \mathrm{HQ}, 25 \mu \mathrm{M}$ CC, and different concentrations of RS. Inset plots of the peak current as a function $\mathrm{HQ}, \mathrm{CC}$, and RS concentrations.

The performance of the GCE/ErGO-cMWCNT/AuNPs sensor for multianalyte detection was evaluated using simultaneous increasing concentrations of $\mathrm{HQ}, \mathrm{CC}$, and RS. The oxidation currents linearly increased in proportion to analyte concentrations. Three well-defined and distinct oxidation peaks for HQ, CC, and RS are observed in Figure 10A. As shown in Figure 10B-D, the linear ranges of HQ, CC, and RS were divided into two, one at low concentrations and the other at high concentrations, as shown in Table 1, resulting in higher sensitivities for lower concentrations. The high sensitivity observed at lower concentrations is related to a more significant number of active sites on the electrode surface, which are progressively reduced as the concentration increases, consequently decreasing sensitivity. However, the calculated LOD (3.3SD/S) of $0.39,0.54$, and $0.61 \mu \mathrm{M}$ for HQ, CC, and RS, respectively, showed the remarkable performance of the GCE/ErGOcMWCNT/AuNPs sensor and the effective synergistic effects of the nanocomposite. This confirms that the CME can be used for simultaneous detection of the three DHB without interference among them.
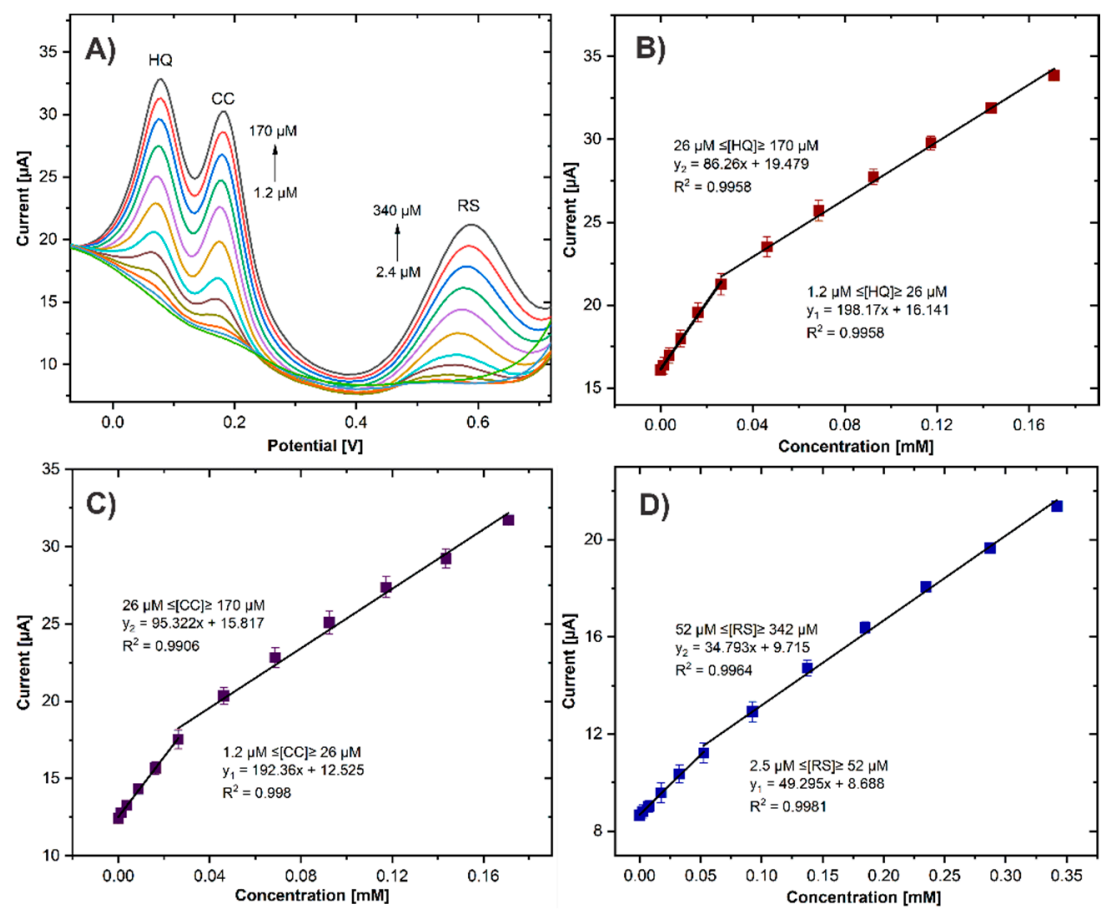

Figure 10. (A) DPVs of GCE/ErGO-cMWCNT/AuNPs in 0.01M PBS (pH 7.0) containing different concentrations of HQ, CC, and RS. (B-D) Plots of the oxidation peak currents as a function of HQ, $\mathrm{CC}$, and RC concentrations, respectively. 
Table 1. Analytical parameters of GCE/ErGO-cMWCNT/AuNPs sensor for multianalyte detection.

\begin{tabular}{ccccc}
\hline Analyte & $\begin{array}{c}\text { Potential } \\
(\mathbf{V})\end{array}$ & $\begin{array}{c}\text { Linear Range } \\
(\boldsymbol{\mu M})\end{array}$ & $\begin{array}{c}\text { Sensitivity } \\
\left(\boldsymbol{\mu} \mathbf{A} . \mathbf{m M . c m} \mathbf{m}^{-2}\right)\end{array}$ & $\begin{array}{c}\text { LOD } \\
(\boldsymbol{\mu M})\end{array}$ \\
\hline HQ & 0.073 & $1.2-26,26-170$ & 1962,854 & 0.39 \\
CC & 0.18 & $1.2-26,26-170$ & 1904,922 & 0.55 \\
RS & 0.58 & $2.5-52,52-342$ & 488,344 & 0.61 \\
\hline
\end{tabular}

Table 2 shows the comparison of the electrochemical parameters obtained in this work with devices designed for multianalyte detection of DHB. The comparative data showed that the electroanalytical properties of this work are comparable or even better concerning previously reported electrochemical sensors for simultaneous DHB detection. For instance, the GCE/ErGO-cMWCNT/AuNPs proposed in this work displays a more extensive linear range to $H Q, C C$, and $R S$ and lower LOD to $H Q$ and $C C$ than those similar based on a 3D carbon nanotube-graphene hybrid decorated with gold nanoparticles [20]. In this work, the functionalization of MWCNT with carboxylic functional groups played an essential role in the good sensitivity towards $\mathrm{DHB}$, because in addition to generating excellent dispersion in solution and enabling uniform electrode layer, it facilitated the adsorption of the DHB in both the electrode surface and the great amount of active edge plans with improved electrocatalytic activity. In addition, Table 2 displays that GCE/ErGO-cMWCNT/AuNPs had a notable performance with lower LOD and more extensive linear range than other similar carbon-based materials reported in the literature, such as graphene screen-printed electrode [46], Au-Pd nanoflower/reduced graphene oxide nanocomposite [47], and Cuporphyrin-poly(styrene sulfonate) functionalized graphene [48]. The high performance of GCE/ErGO-cMWCNT/AuNPs expressed the notable synergistic effects granted to the nanocomposite.

Table 2. Comparison of similar methods for the simultaneous determination of HQ, CC, and RS.

\begin{tabular}{|c|c|c|c|c|c|c|c|c|}
\hline \multirow{2}{*}{ Modified Electrode } & \multirow{2}{*}{ Real Sample } & \multicolumn{3}{|c|}{ Linear Range $(\mu \mathrm{M})$} & \multicolumn{3}{|c|}{ Detection Limit $(\mu \mathrm{M})$} & \multirow{2}{*}{ References } \\
\hline & & HQ & $\mathrm{CC}$ & RS & HQ & $\mathrm{CC}$ & RS & \\
\hline 3D CNT-Gr/AuNPs/GCE & Tap, river water & $2-80$ & $2-80$ & $2-80$ & 0.8 & 0.95 & 0.1 & [20] \\
\hline AuNPs/NfCAG/Gr-SPE & Tap, mineral water & $0.2-75$ & $0.2-50$ & $0.2-125$ & 0.014 & 0.017 & 0.05 & {$[33]$} \\
\hline $\begin{array}{c}\text { ERGO- } \\
\text { poly }(\mathrm{PR}) / \mathrm{AuNPs} / \mathrm{GCE}\end{array}$ & Wastewater and cosmetic sample & $0.1-90$ & $0.4-90$ & $4-350$ & 0.053 & 0.053 & 0.079 & {$[43]$} \\
\hline Gr/SPE & Tap water & $1-50$ & $1-50$ & $1-50$ & 2.7 & 1.7 & 2.4 & {$[46]$} \\
\hline $\mathrm{Au} @ \mathrm{PdNF} / \mathrm{RGO} / \mathrm{GCE}$ & Tap, river, and lake water & $1.6-100$ & $2.5-100$ & $2.0-100$ & 0.5 & 0.8 & 0.7 & [47] \\
\hline PSS-Gr@Cu-TCPP/GCE & Lake, tap water & $1-200$ & $0.08-120$ & $5-100$ & 1 & 0.08 & 5 & [48] \\
\hline MWCNT@rGONR/GCE & Tap, river water & $15-921$ & $15-1101$ & $15-1301$ & 3.89 & 1.73 & 5.77 & [49] \\
\hline $\mathrm{UiO}-66 / \mathrm{MC}-3 / \mathrm{GCE}$ & Tap, lake water & $0.5-100$ & $0.4-100$ & $30-400$ & 0.056 & 0.072 & 3.51 & {$[50]$} \\
\hline $\begin{array}{c}\text { GCE/ErGO- } \\
\text { cMWCNT/AuNPs }\end{array}$ & Tap water, skin-lightening cream & $1.2-170$ & $1.2-170$ & $2.5-342$ & 0.39 & 0.54 & 0.61 & This work \\
\hline
\end{tabular}

MWCNT, multiwalled carbon nanotube; rGONR, reduced graphene; NfCAG, Nafion-multi-walled carbon nanotubes aerogel; AuNPs, gold nanoparticles modified; Gr-SPE, graphene screen-printed electrode; NF, Nanoflower; rGO, reduced graphene oxide; Cu-porphyrin, CuTCPP; PSS-Gr, poly(styrene sulfonate) functionalized graphene; ERGO-poly(PR), electrochemically reduced graphene oxide-poly(Procion Red MX-5B); MOF-UiO-66, zirconium-based; MC, mesoporous carbon.

\subsection{Reproduciblity and Stability}

The reproducibility of the modified electrode GCE/ErGO-cMWCNT/AuNPs is crucial for the accurate monitoring of $\mathrm{HQ}, \mathrm{CC}$, and RS. Five electrodes were prepared by the same procedure and the electrochemical responses towards $0.2 \mathrm{mM}$ of HQ, CC, and RS (Figure 11A) were compared. The results revealed that the relative standard deviations (RSD) of current peaks were $2.55 \%, 2.69 \%$, and $2.81 \%$, respectively. Thus, the electrode reproducibility was associated with better dispersion of the cMWCNT and the highly 
controlled electrochemical process for ErGO and AuNPs synthesis, which helps to generate a more homogeneous composite onto the electrode surface.
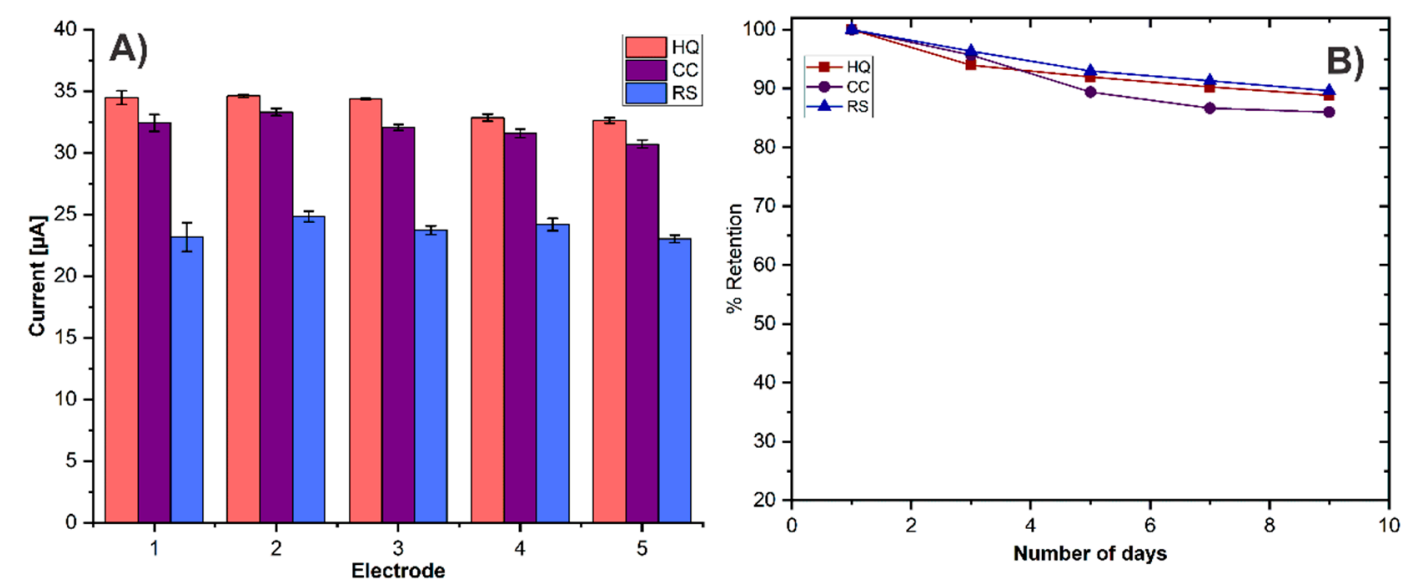

Figure 11. (A) Reproducibility of GCE/ErGO-cMWCNT/AuNPs of 5 different electrodes, (B) stability.

The stability of the GCE/ErGO-cMWCNT/AuNPs sensor was also studied; the electrode was kept at room temperature $\left(25^{\circ} \mathrm{C}\right)$ in the air for nine days. During this period, the DPV detection was carried out under the same conditions every day. The stability was calculated by comparing the percentage (\%) of current retention of the initial response. The $\%$ retention to HQ, CC, and RS reached $89 \%, 86 \%$, and $90 \%$ of the initial value, respectively, manifesting high stability.

\subsection{Real Sample Analysis}

To demonstrate the applicability of the GCE/ErGO-cMWCNT/AuNPs sensor for the simultaneous quantitative detection of the DHB isomers, tap water and a skin-lightening commercial cream were tested. The results are summarized in Table 3. The concentrations of the DHB were calculated from the calibration plot, and the samples were evaluated by triplicate. Table 3 shows the recoveries of the samples in tap water, found in the range of $104.7-113.64 \%$ for HQ, $104.88-106.08 \%$ for CC, and $101.58-110.09 \%$ for RS. The obtained recoveries of the cosmetic sample were calculated to be $101.9-103.09 \%$ for $\mathrm{HQ}$, $99.59-103.59 \%$ for CC, and $99.59-105.09 \%$ for RS. The satisfactory results demonstrate the feasibility of using GCE/ErGO-cMWCNT/AuNPs for the electrochemical detection of HQ, CC, and RS in environmental and cosmetic samples. Hence, the results confirmed that the proposed method has the potential for timely implementation and good reliability for the multiple detections of $\mathrm{HQ}, \mathrm{CC}$, and RS from different matrices.

Table 3. Determination of HQ, CC, and RS in tap water and skin-lightening cream at the GCE/ErGO-cMWCNT/AuNPs $(n=3)$.

\begin{tabular}{|c|c|c|c|c|c|c|c|c|c|c|c|c|c|}
\hline \multirow[t]{2}{*}{ Scheme 3.} & \multirow[t]{2}{*}{ Included $(\mu \mathrm{M})$} & \multicolumn{3}{|c|}{ Spiked $(\mu \mathrm{M})$} & \multicolumn{3}{|c|}{ Found $(\mu \mathrm{M})$} & \multicolumn{3}{|c|}{ Recovery (\%) } & \multicolumn{3}{|c|}{$\% \operatorname{RSD}(n=3)$} \\
\hline & & HQ & $\mathrm{CC}$ & RS & HQ & $\mathrm{CC}$ & RS & HQ & $\mathrm{CC}$ & RS & HQ & $\mathrm{CC}$ & RS \\
\hline \multirow[t]{3}{*}{ Tap water } & - & 0.05 & 0.05 & 0.1 & 0.056 & 0.052 & 0.105 & 113.64 & 105.40 & 101.58 & 8.97 & 3.06 & 4.75 \\
\hline & - & 0.1 & 0.1 & 0.2 & 0.11 & 0.106 & 0.22 & 110.46 & 106.08 & 110.09 & 4.42 & 1.14 & 3.21 \\
\hline & - & 0.15 & 0.15 & 0.3 & 0.157 & 0.157 & 0.321 & 104.70 & 104.88 & 107.18 & 8.54 & 3.46 & 5.22 \\
\hline Skin- & $0.111 \mathrm{HQ}$ & - & 0.11 & 0.22 & 0.114 & 0.110 & 0.253 & 103.09 & 100.50 & 105.09 & 1.92 & 6.12 & 1.09 \\
\hline lightening & $0.14 \mathrm{HQ}$ & - & 0.14 & 0.28 & 0.150 & 0.145 & 0.286 & 107.26 & 103.58 & 102.41 & 2.38 & 5.47 & 7.19 \\
\hline cream & $0.17 \mathrm{HQ}$ & - & 0.17 & 0.34 & 0.173 & 0.169 & 0.344 & 101.79 & 99.59 & 101.179 & 4.12 & 0.95 & 0.47 \\
\hline
\end{tabular}




\section{Conclusions}

The GCE/ErGO-cMWCNT/AuNPs sensor presented a synergistic effect in enhanced conductivity, electroactivity, and enlarged electroactive surface area, associated with the $3 \mathrm{D}$ network formed by the strong $\pi-\pi$ stacking interaction between ErGO and cMWCNT with well-defined nanopores, and the active catalytic sites of AuNPs. Additionally, the carboxylated MWCNT provided the nanocomposite with improved electrocatalytic properties towards the DHB detection compared to the pristine MWCNT. The GCE/ErGOcMWCNT / AuNPs sensor allowed simultaneous detection of HQ, CC, and RS by monitoring their distinctive electrocatalytic oxidation current. The electrode provided acceptable linear ranges in the concentration range of $1.2-170 \mu \mathrm{M}$ for HQ and CC and $2.4-400 \mu \mathrm{M}$ for RS, as well as low detection limits for $\mathrm{HQ}, \mathrm{CC}$, and RS of $0.39 \mu \mathrm{M}, 0.54 \mu \mathrm{M}$, and $0.61 \mu \mathrm{M}$, respectively. In addition, the electrochemical sensor showed good reproducibility, stability, and relevant results in the recovery rates of tap water and skin-lightening cosmetic cream. The results indicate that the proposed GCE/ErGO-cMWCNT/AuNPs electrochemical sensor has a great potential for the simultaneous, precise, and easy-to-handle detection of DHB in complex samples with high sensitivity.

Supplementary Materials: The following are available online at https://www.mdpi.com/article/ 10.3390/bios11090321/s1, Figure S1: Raman spectra of GO and ErGO, Figure S2: Cyclic voltammetry of (a) GCE/AuNPs, (c) GCE/cMWCNT/AuNPs, (e) GCE/ErGO/AuNPs, (g) GCE/ErGOcMWCNT/AuNPs at different scan rates in $5.0 \mathrm{mM}\left[\mathrm{Fe}(\mathrm{CN})_{6}\right]^{3-/ 4-}$ containing PBS $0.01 \mathrm{M}$. The linear relationship between the anodic and cathodic peak currents versus root of the scan rate of (b) GCE/AuNPs, (d) GCE/cMWCNT/AuNPs, (f) GCE/ErGO/AuNPs, (h) GCE/ErGOcMWCNT/AuNPs.

Author Contributions: A.D.-A.: investigation, methodology, formal analysis, writing-original draft. R.B.D.: conceptualization, validation, writing — review and editing. E.A.Z.-C.: writing-review and editing, supervision, funding acquisition. All authors have read and agreed to the published version of the manuscript.

Funding: This project was financed by the National Council for Science and Technology of Mexico (CONACYT), grant number CB2016-288802-Q.

Institutional Review Board Statement: Not applicable.

Informed Consent Statement: Not applicable.

Data Availability Statement: Not applicable.

Acknowledgments: We wish to thank CONACYT for the scholarship awarded to Angélica Domínguez-Aragón (701394). We also wish to thank the Laboratorio Nacional de Nanotecnología (CIMAV), Claudia Hernández, Miguel Orozco, Manuel Román, Pedro Pizá-Ruíz, Karla Campos for their valuable collaboration during this research.

Conflicts of Interest: The authors declare no conflict of interest.

\section{References}

1. Pifer, J.W.; Hearne, F.T.; Swanson, F.A.; O'Donoghue, J.L. Mortality study of employees engaged in the manufacture and use of hydroquinone. Int. Arch. Occup. Environ. Health 1995, 67, 267-280. [CrossRef]

2. Tse, T.W. Hydroquinone for skin lightening: Safety profile, duration of use and when should we stop? J. Dermatol. Treat. 2010, 21, 272-275. [CrossRef]

3. Trevors, J.T.; Basaraba, J. Toxicity of benzoquinone and hydroquinone in short-term bacterial bioassays. Bull. Environ. Contam. Toxicol. 1980, 25, 672-675. [CrossRef] [PubMed]

4. DeCaprio, A.P. The toxicology of hydroquinone-Relevance to occupational and environmental exposure. Crit. Rev. Toxicol. 1999, 29, 283-330. [CrossRef]

5. Hebeda, C.B.; Pinedo, F.J; Bolonheis, S.M.; Ferreira, Z.F.; Muscará, M.N.; Teixeira, S.A.; Farsky, S.H.P. Intracellular mechanisms of hydroquinone toxicity on endotoxin-activated neutrophils. Arch. Toxicol. 2012, 86, 1773-1781. [CrossRef] [PubMed]

6. Karim, F.; Fakhruddin, A.N.M. Recent advances in the development of biosensor for phenol: A review. Rev. Environ. Sci. Biotechnol. 2012, 11, 261-274. [CrossRef] 
7. Maleki, N.; Kashanian, S.; Maleki, E.; Nazari, M. A novel enzyme based biosensor for catechol detection in water samples using artificial neural network. Biochem. Eng. J. 2017, 128, 1-11. [CrossRef]

8. Barbaud, A.; Modiano, P.; Cocciale, M.; Reichert, S.; Schmutz, J.L. The topical application of resorcinol can provoke a systemic allergic reaction. Br. J. Dermatol. 1996, 135, 1014-1015. [CrossRef] [PubMed]

9. Lynch, B.S.; Delzell, E.S.; Bechtel, D.H. Toxicology review and risk assessment of resorcinol: Thyroid effects. Regul. Toxicol. Pharmacol. 2002, 36, 198-210. [CrossRef] [PubMed]

10. Chen, D.; Zhou, H.; Li, H.; Chen, J.; Li, S.; Zheng, F. Self-template synthesis of biomass-derived 3D hierarchical N-doped porous carbon for simultaneous determination of dihydroxybenzene isomers. Sci. Rep. 2017, 7, 14985. [CrossRef]

11. Zhou, H.-F.; Li, S.-X.; Wu, Y.-J.; Chen, D.-J.; Li, Y.-H.; Zheng, F.-Y.; Yu, H.-W. Nitrogen-doped carbon spheres surface modified with in situ synthesized Au nanoparticles as electrochemical selective sensor for simultaneous detection of trace nitrophenol and dihydroxybenzene isomers. Sens. Actuators B 2016, 237, 487-494. [CrossRef]

12. Tanaka, K. Resorcinol. J. Synth. Org. Chem. Jpn. 1985, 43, 262. [CrossRef]

13. Rodríguez, M.C.; Rivas, G.A. Glassy carbon paste electrodes modified with polyphenol oxidase: Analytical applications. Anal. Chim. Acta 2002, 459, 43-51. [CrossRef]

14. Yuan, D.; Chen, S.; Hu, F.; Wang, C.; Yuan, R. Non-enzymatic amperometric sensor of catechol and hydroquinone using Pt-Au-organosilica@chitosan composites modified electrode. Sens. Actuators B Chem. 2012, 168, 193-199. [CrossRef]

15. Ye, Z.; Wang, Q.; Qiao, J.; Xu, Y.; Li, G. In situ synthesis of sandwich MOFs on reduced graphene oxide for electrochemical sensing of dihydroxybenzene isomers. Analyst 2019, 144, 2120-2129. [CrossRef]

16. Zheng, X.; Hu, Y.; Li, H.; Han, B.; Lin, R.; Huang, B. N-doped carbon nanotube frameworks modified electrode for the selective sensing of hydroquinone and catechol. J. Electroanal. Chem. 2020, 861, 113968. [CrossRef]

17. Lu, J.Y.; Yu, Y.S.; Chen, T.B.; Chang, C.F.; Tamulevičius, S.; Erts, D.; Wu, K.C.W.; Gu, Y. Fabrication of an extremely cheap poly(3,4-ethylenedioxythiophene) modified pencil lead electrode for effective hydroquinone sensing. Polymers 2021, 13, 343. [CrossRef]

18. Yang, J.; Deng, S.; Lei, J.; Ju, H.; Gunasekaran, S. Electrochemical synthesis of reduced graphene sheet-AuPd alloy nanoparticle composites for enzymatic biosensing. Biosens. Bioelectron. 2011, 29, 159-166. [CrossRef]

19. Yin, D.; Liu, J.; Bo, X.; Guo, L. Cobalt-iron selenides embedded in porous carbon nanofibers for simultaneous electrochemical detection of trace of hydroquinone, catechol and resorcinol. Anal. Chim. Acta 2020, 1093, 35-42. [CrossRef]

20. Chen, T.-W. Simultaneous Determination of Dihydroxybenzene Isomers using Glass Carbon Electrode Modified with 3D CNT-graphene Decorated with Au Nanoparticles. Int. J. Electrochem. Sci. 2019, 14, 7037-7046. [CrossRef]

21. Butwong, N.; Kunawong, T.; Luong, J.H.T. Simultaneous Analysis of Hydroquinone, Arbutin, and Ascorbyl Glucoside Using a Nanocomposite of Ag@AgCl Nanoparticles, Ag2S Nanoparticles, Multiwall Carbon Nanotubes, and Chitosan. Nanomaterials 2020, 10, 1583. [CrossRef]

22. Torrinha, Á.; Oliveira, T.M.B.F.; Ribeiro, F.W.P.; Correia, A.N.; Lima-Neto, P.; Morais, S. Application of Nanostructured CarbonBased Electrochemical (Bio)Sensors for Screening of Emerging Pharmaceutical Pollutants in Waters and Aquatic Species: A Review. Nanomaterials 2020, 10, 1268. [CrossRef] [PubMed]

23. Mani, V.; Chen, S.M.; Lou, B.S. Three dimensional graphene oxide-carbon nanotubes and graphene-carbon nanotubes hybrids. Int. J. Electrochem. Sci. 2013, 8, 11641-11660.

24. Dang, V.T.; Nguyen, D.D.; Cao, T.T.; Le, P.H.; Tran, D.L.; Phan, N.M.; Nguyen, V.C. Recent trends in preparation and application of carbon nanotube-graphene hybrid thin films. Adv. Nat. Sci. Nanosci. Nanotechnol. 2016, 7, 033002. [CrossRef]

25. Filik, H.; Avan, A.A. Review on applications of carbon nanomaterials for simultaneous electrochemical sensing of environmental contaminant dihydroxybenzene isomers. Arab. J. Chem. 2020, 13, 6092-6105. [CrossRef]

26. Wang, X.; Yang, L.; Jin, X.; Zhang, L. Electrochemical determination of estrogenic compound bisphenol F in food packaging using carboxyl functionalized multi-walled carbon nanotubes modified glassy carbon electrode. Food Chem. 2014, 157, 464-469. [CrossRef]

27. Carneiro, P.; Morais, S.; Pereira, M.C. Nanomaterials towards Biosensing of Alzheimer's Disease Biomarkers. Nanomaterials 2019, 9, 1663. [CrossRef]

28. Hummers, W.S.; Offeman, R.E. Preparation of Graphitic Oxide. J. Am. Chem. Soc. 1958, 80, 1339. [CrossRef]

29. Hoa, L.M.T. Characterization of multi-walled carbon nanotubes functionalized by a mixture of $\mathrm{HNO}_{3} / \mathrm{H}_{2} \mathrm{SO}_{4}$. Diam. Relat. Mater. 2018, 89, 43-51. [CrossRef]

30. Yu, H.; Li, R.; Song, K. Amperometric determination of nitrite by using a nanocomposite prepared from gold nanoparticles, reduced graphene oxide and multi-walled carbon nanotubes. Microchim. Acta 2019, 186, 624. [CrossRef]

31. Kıranşan, K.D.; Topçu, E. Free-standing and Flexible $\mathrm{MoS}_{2} / \mathrm{rGO}$ Paper Electrode for Amperometric Detection of Folic Acid. Electroanalysis 2018, 30, 810-818. [CrossRef]

32. Elgrishi, N.; Rountree, K.J.; McCarthy, B.D.; Rountree, E.S.; Eisenhart, T.T.; Dempsey, J.L. A Practical Beginner's Guide to Cyclic Voltammetry. J. Chem. Educ. 2018, 95, 197-206. [CrossRef]

33. Avan, A.A.; Filik, H. Simultaneous electrochemical sensing of dihydroxybenzene isomers at multi-walled carbon nanotubes aerogel/gold nanoparticles modified graphene screen-printed electrode. J. Electroanal. Chem. 2020, 878, 114682. [CrossRef] 
34. Yang, S.; Yang, M.; Yao, X.; Fa, H.; Wang, Y.; Hou, C. A zeolitic imidazolate framework/carbon nanofiber nanocomposite based electrochemical sensor for simultaneous detection of co-existing dihydroxybenzene isomers. Sens. Actuators B Chem. 2020, 320, 128294. [CrossRef]

35. Laurila, T.; Sainio, S.; Caro, M.A. Hybrid carbon based nanomaterials for electrochemical detection of biomolecules. Prog. Mater. Sci. 2017, 88, 499-594. [CrossRef]

36. Bi, H.; Li, Y.; Liu, S.; Guo, P.; Wei, Z.; Lv, C.; Zhang, J.; Zhao, X.S. Carbon-nanotube-modified glassy carbon electrode for simultaneous determination of dopamine, ascorbic acid and uric acid: The effect of functional groups. Sens. Actuators $B$ Chem. 2012, 171-172, 1132-1140. [CrossRef]

37. Moraes, F.C.; Cabral, M.F.; Mascaro, L.H.; MacHado, S.A.S. The electrochemical effect of acid functionalisation of carbon nanotubes to be used in sensors development. Surf. Sci. 2011, 605, 435-440. [CrossRef]

38. Goulart, L.A.; De Moraes, F.C.; Mascaro, L.H. Influence of the different carbon nanotubes on the development of electrochemical sensors for bisphenol A. Mater. Sci. Eng. C 2016, 58, 768-773. [CrossRef] [PubMed]

39. Yen, M.-Y.; Hsiao, M.-C.; Liao, S.-H.; Liu, P.-I.; Tsai, H.-M.; Ma, C.-C.M.; Pu, N.-W.; Ger, M.-D. Preparation of graphene/multiwalled carbon nanotube hybrid and its use as photoanodes of dye-sensitized solar cells. Carbon 2011, 49, 3597-3606. [CrossRef]

40. Wu, F.; Zhao, J.; Han, D.; Zhao, S.; Zhu, R.; Cui, G. A three-electrode integrated electrochemical platform based on nanoporous gold for the simultaneous determination of hydroquinone and catechol with high selectivity. Analyst 2021, 146, 232-243. [CrossRef]

41. Huang, R.; Liao, D.; Chen, S.; Yu, J.; Jiang, X. A strategy for effective electrochemical detection of hydroquinone and catechol: Decoration of alkalization-intercalated $\mathrm{Ti}_{3} \mathrm{C}_{2}$ with MOF-derived N-doped porous carbon. Sens. Actuators B Chem. 2020, 320, 128386. [CrossRef]

42. Sheng, Z.H.; Zheng, X.Q.; Xu, J.Y.; Bao, W.J.; Wang, F.B.; Xia, X.H. Electrochemical sensor based on nitrogen doped graphene: Simultaneous determination of ascorbic acid, dopamine and uric acid. Biosens. Bioelectron. 2012, 34, 125-131. [CrossRef]

43. Edris, N.M.M.A.; Sulaiman, Y. Ultrasensitive voltammetric detection of benzenediol isomers using reduced graphene oxide-azo dye decorated with gold nanoparticles. Ecotoxicol. Environ. Saf. 2020, 203, 111026. [CrossRef] [PubMed]

44. Velmurugan, M.; Karikalan, N.; Chen, S.-M.; Cheng, Y.-H.; Karuppiah, C. Electrochemical preparation of activated graphene oxide for the simultaneous determination of hydroquinone and catechol. J. Colloid Interface Sci. 2017, 500, 54-62. [CrossRef]

45. Laviron, E. General expression of the linear potential sweep voltammogram in the case of diffusionless electrochemical systems. J. Electroanal. Chem. 1979, 101, 19-28. [CrossRef]

46. Aragó, M.; Ariño, C.; Dago, À.; Díaz-Cruz, J.M.; Esteban, M. Simultaneous determination of hydroquinone, catechol and resorcinol by voltammetry using graphene screen-printed electrodes and partial least squares calibration. Talanta 2016, 160, 138-143. [CrossRef] [PubMed]

47. Chen, Y.; Liu, X.; Zhang, S.; Yang, L.; Liu, M.; Zhang, Y.; Yao, S. Ultrasensitive and simultaneous detection of hydroquinone, catechol and resorcinol based on the electrochemical co-reduction prepared Au-Pd nanoflower/reduced graphene oxide nanocomposite. Electrochim. Acta 2017, 231, 677-685. [CrossRef]

48. Zhang, C.; Han, M.; Yu, L.; Qu, L.; Li, Z. Fabrication an electrochemical sensor based on composite of Cu-TCPP nanosheets and PSS functionalized graphene for simultaneous and sensitive determination of dihydroxybenzene isomers. J. Electroanal. Chem. 2021, 890, 115232. [CrossRef]

49. Yang, S.; Yang, M.; Liu, Q.; Wang, X.; Fa, H.; Wang, Y.; Hou, C. An Ultrasensitive Electrochemical Sensor Based on Multiwalled Carbon Nanotube@Reduced Graphene Oxide Nanoribbon Composite for Simultaneous Determination of Hydroquinone, Catechol and Resorcinol. J. Electrochem. Soc. 2019, 166, B547-B553. [CrossRef]

50. Deng, M.; Lin, S.; Bo, X.; Guo, L. Simultaneous and sensitive electrochemical detection of dihydroxybenzene isomers with UiO-66 metal-organic framework/mesoporous carbon. Talanta 2017, 174, 527-538. [CrossRef] 